Research Article

\title{
Comparison of effects of isoniazid plus ART and ART only regimen on the incidence of tuberculosis and HIV progression in HIV positive patients: a retrospective cohort study at two hospitals in Addis Ababa, Ethiopia
}

\author{
Dumessa Edessa $^{1}$, Tolera Woldeyes ${ }^{2}$, Workineh Shibeshi ${ }^{1 *}$
}

\begin{abstract}
${ }^{1}$ Department of Pharmacology and Clinical Pharmacy, School of Pharmacy, Addis Ababa University, P.O. Box 9086, Addis Ababa, Ethiopia

${ }^{2}$ Department of Internal Medicine, School of Medicine, Addis Ababa University, P.O. Box 9086, Addis Ababa, Ethiopia
\end{abstract}

Received: 31 October 2013 Accepted: 13 November 2013

*Correspondence to:

Workineh Shibeshi,

Email:shibeshiworkineh@gmail.com

(C) 2014 Edessa D et al. This is an open-access article distributed under the terms of the Creative Commons Attribution Non-Commercial License, which permits unrestricted non-commercial use, distribution, and reproduction in any medium, provided the original work is properly cited.

\begin{abstract}
Background: Tuberculosis is a major opportunistic complication of HIVinfection. Antiretroviral therapy (ART) lowers incidence of tuberculosis (TB) but may not be sufficient to control HIV-related tuberculosis, implying a need for additional interventions. The aim of this study was to compare the effects of isoniazid preventive therapy (IPT) plus ART and ART only regimens on the incidence of active TB and HIV progression in HIV positive patients.
\end{abstract}

Methods: The retrospective cohort study was conducted at Tikur Anbessa Specialized Hospital and Zewditu Memorial Hospital on 185 patients receiving IPT plus ART and 557 patients receiving ART only. Incidence rates (IR) were used to determine incidence rates of tuberculosis. Time to AIDS and TB event were compared using student t-test. Risks of the outcomes were identified using regression models.

Results: The study showed a reduced tuberculosis incidence rate from 7.44 to 1.8 cases/100 person-years [PYs] by IPT plus ART compared to ART only. In reference to ART alone, the IPT plus ART significantly reduced risks of active TB (adjusted odds ratio [AOR] 0.24; 95\% CI 0.09-0.63; $\mathrm{P}=0.004)$ and had about 16 months of TB protection $(\mathrm{P}<0.001)$. In addition, the IPT plus ART delayed HIV progression to AIDS more significantly than the ART only $(\mathrm{P}=0.029)$. However, it increased risks of adverse events (AOR 3.33; 95\% CI 1.35-8.19; $\mathrm{P}=0.01$ ) more than the ART only.

Conclusions: The wider use of IPT with ART impacts more on incidence of tuberculosis and time to AIDS while simultaneously increasing risks of adverse events than the ART only.

Keywords: Antiretroviral therapy, HIV-infected, Tuberculosis, Isoniazid preventive therapy

\section{INTRODUCTION}

Tuberculosis (TB) is one of the most common opportunistic complications of human immunodeficiency virus (HIV) infection, and is the first leading cause of death among HIV-TB co-infected individuals., ${ }^{1,2,3}$ isoniazid preventive therapy (IPT) reduces tuberculosis incidence significantly, but is not widely implemented. ${ }^{1}$ The scale up of antiretroviral therapy (ART) has transformed HIV infection into a chronic and manageable disease, but the successes recorded can easily be reversed by the high burden of tuberculosis co-infection. ${ }^{4}$
Globally, about 8.7 million people per year are infected with tuberculosis. ${ }^{5}$ One-third of the world's population is believed to be latently infected with Mycobacterium tuberculosis (MTB), however, majority of those infected will never have clinical symptoms. ${ }^{6,7}$ HIV infection by compromising cell-mediated immunity is the most potent known risk factor for the reactivation of latent Mycobacterium tuberculosis infection to active TB disease. ${ }^{6,8}$ The lifetime risk of progression from latent tuberculosis infection to active disease is about $10 \%$ in the general population while HIV positive persons who are infected with MTB have a $30 \%$ lifetime risk of 
developing active tuberculosis; and this risk increases as immune deficiency worsens. ${ }^{6,8,9}$

The control of these epidemics, therefore, requires the consideration of innovative bold interventions and critical thinking. ${ }^{10}$ ART and IPT are the two useful tuberculosis preventive strategies in HIV-infection. ${ }^{11}$ However, limited data suggest that IPT or ART can independently reduce tuberculosis disease and mortality in patients infected with HIV. ${ }^{11}$ This initiated different investigators to undertake randomized clinical trials investigating the combined effects of IPT and ART in adults. ${ }^{12}$ Because of variability of clinical cohorts in different nations, such evidences from other countries may lack applicability in Ethiopia. In Ethiopia, since 2005, access to ART has been almost universal and free of charge to all individuals who qualify for treatment according to national guidelines. Despite provision of the drugs, data that compared the effects of IPT plus ART and ART only regimen on the incidence of TB and HIV progression are not present in Ethiopia. Hence, our present study is primarily designed to identify whether or not there is a difference in the reduction of risks of tuberculosis incidence and HIV progression by treatment with IPT plus ART compared to ART only regimen in HIV positive patients.

\section{METHODS}

\section{Study design and sites}

The study was a retrospective cohort study undertaken at Tikur Anbessa Specialized Hospital and Zewditu Memorial Hospital ART clinics from February 2013 to May 2013. These sites have existing programs for the prevention of tuberculosis and HIV treatment.

\section{Inclusion and exclusion criteria}

The study participants were selected from a sample of Peoples Living with HIV/AIDS (PLHIV) enrolled into the chronic HIV care follow-up from September 11, 2009 to March 31, 2012. HIV-infected male or female adult patients (age $\geq 18$ years) eligible for inclusion in this analysis were those who had made at least one visit to the hospital clinic between the dates of September 11, 2009 and March 31, 2012; and who received their primary care (ART or IPT plus ART) from the clinics. Patients with tuberculosis confirmed before admission into the study or elevated/altered liver function tests (LFTs) (values 5 times above the normal limits in asymptomatic patients or 3 times above the normal limits in symptomatic patients) at baseline; and those patients neither on IPT plus ART nor on ART alone were excluded. Patients for whom the date (month and year) of starting treatment was unknown were also excluded.

\section{Sampling method}

The study was designed and powered to evaluate the study outcomes (active TB, HIV progression to AIDS and incidence of adverse event) in HIV-infected patients with a target sample of 742 HIV-infected patients stratified into two groups - 185 patients as exposed group [those receiving IPT plus ART] and 557 patients as control group [those receiving ART only]. Sampling frame was prepared using medical registration number (MRN) of patients enrolled into the hospitals who received ART or IPT plus ART during September 11, 2009 to March 31, 2012 and simple random sampling was used for sampling using list of the identified patients based on their MRN.

\section{Study objectives and endpoints}

Key primary endpoint was active tuberculosis based upon microbiological diagnosis or as a defined clinical syndrome. Time to active tuberculosis event from the initiation of preventive therapy was also considered as primary endpoint. Major secondary endpoint was HIV progression to AIDS (defined in terms of incidence of AIDS or time/interval to AIDS, types of HIV-related diseases, and change in CD4 count). Incidence of adverse events documented (defined as an appreciably harmful or unpleasant reaction which predicts hazard from future administration and warrants prevention or specific treatment, or alteration of the dosage regimen, or withdrawal of the product) was included as secondary outcome.

\section{Data collection}

Identification of patients on IPT plus ART and ART only was made for HIV-infected patients starting from February 2013. To obtain complete ascertainment and baseline data of the patients identified at the two HIV care study clinics, medical record abstraction was conducted. Data was abstracted from individual patient records at the clinics using customized data collection forms. The data abstraction forms were extensively piloted before implementation and data abstractors were trained to collect the data. All forms were reviewed for completeness, and then data were entered into an SPSS database. A patient's follow-up time would end either at his/her last visit to the HIV clinic or the date of administrative censoring, March 31, 2013. CD4 cell count data were those reported closest in time to the reference variable.

\section{Data analysis}

Descriptive statistics were employed to summarize baseline demographic and clinical characteristics of patients. Student t-test was used for estimating time to tuberculosis event and time to AIDS between the comparison groups. Incidence rates (IR) per $100 \mathrm{PYs}$ and odds ratio (OR) were employed to determine incidence rates and risks of TB. Regression analysis was used for odds ratios and analyses adjusted for covariates. The analyses followed an intention-to-treat approach. Significance testing was done using two-sided p-values and $95 \%$ confidence intervals $(95 \% \mathrm{CI})$. The data was analyzed with the use of SPSS software, version 16.0. 


\section{Ethical consideration}

The study was approved by the Addis Ababa University, School of Pharmacy, Ethics Review Board (ERB/SOP/24/05/2013) research and ethics committee of Department of Internal Medicine (No. IM/402/2013) and Ethical Clearance Committee of Addis Ababa Regional Health Bureau (No. 4240/227). Permission to data of patients was officially obtained from the administrative offices of Tikur Anbessa Specialized Hospital and Zewditu Memorial Hospital from where study participants were selected.

\section{RESULTS}

Data were collected from the medical records of 742 $\mathrm{HIV}$-infected patients. Analysis was made in comparison of two groups of study cohorts; cohort with treatment by IPT plus ART $(\mathrm{N}=185)$ and cohort with treatment by ART only $(\mathrm{N}=557)$. Data shows baseline characteristics of the 742 HIV-infected patients (Table 1). The demographic characteristics of the two study groups were almost comparable. The median duration of follow-up for the cohort was 25 months.

Table 1: Baseline demographic and clinical characteristics of the study cohorts stratified by treatment category at TASH and ZMH ART clinics, Ethiopia, 2013.

\begin{tabular}{|c|c|c|c|c|}
\hline Characteristics & ART and IPT $(\mathrm{N}=185)$ & ART Only (N=557) & Overall ( $\mathrm{N}=742)$ & P-value \\
\hline \multicolumn{5}{|l|}{ Age (Years) } \\
\hline Median & 38 & 35 & 35 & $0.026^{*}$ \\
\hline Interquartile range & $32-43$ & $30-42$ & $30-42$ & \\
\hline Male sex-No $(\%)$ & $88(47.6)$ & $239(42.9)$ & $327(44.1)$ & 0.23 \\
\hline \multicolumn{5}{|l|}{ Weight (Kg) } \\
\hline Median & 62 & 56 & 57 & $<0.001 *$ \\
\hline Interquartile range & $53-69$ & $49-64$ & $50-65$ & \\
\hline \multicolumn{5}{|l|}{ Drug Addiction-No (\%) } \\
\hline None & $124(67)$ & $413(74.1)$ & $537(72.4)$ & 0.65 \\
\hline Alcohol & $10(5.4)$ & $41(7.4)$ & $51(6.9)$ & \\
\hline Tobacco & $3(1.6)$ & $3(0.5)$ & $6(0.8)$ & \\
\hline Khat & $3(1.6)$ & $8(1.4)$ & $11(1.5)$ & \\
\hline Khat/shisha & $3(1.6)$ & $2(0.4)$ & $23(12.4)$ & \\
\hline Alcohol/tobacco & $19(10.3)$ & $57(10.2)$ & $76(10.2)$ & \\
\hline No data & $23(12.4)$ & $33(5.9)$ & $56(7.5)$ & \\
\hline Previous TB-No $(\%)$ & $9(4.9)$ & $27(4.8)$ & $36(4.8)$ & 0.20 \\
\hline \multicolumn{5}{|c|}{ Documented OIs-No (\%) } \\
\hline None & $109(58.9)$ & $377(67.7)$ & $486(65.5)$ & \\
\hline 1 documented OI & $42(22.7)$ & $97(17.4)$ & $139(18.7)$ & \\
\hline 2 documented OIs & $17(9.2)$ & $40(7.2)$ & $57(7.7)$ & \\
\hline 3 documented OIs & $7(3.8)$ & $14(2.5)$ & $21(2.8)$ & \\
\hline 5 documented OIs & $1(0.5)$ & $1(0.2)$ & $2(0.3)$ & \\
\hline 7 documented OIs & & $1(0.2)$ & $1(0.1)$ & \\
\hline \multicolumn{5}{|c|}{ Baseline AIDS stage - No (\%) } \\
\hline I & $19(10.3)$ & $110(19.70)$ & $129(17.4)$ & \\
\hline II & $76(41.1)$ & $198(35.50)$ & $274(36.9)$ & \\
\hline III & $69(37.3)$ & $195(35.0)$ & $264(35.6)$ & \\
\hline IV & $21(11.4)$ & $54(9.70)$ & $75(10.10)$ & \\
\hline \multicolumn{5}{|c|}{ Baseline CD4 cell counts $($ Cells/mL) } \\
\hline Median & 322 & 148 & 180 & $<0.001 *$ \\
\hline Interquartile range & $202-499$ & $81-235$ & $96-287$ & \\
\hline \multicolumn{5}{|l|}{ ART regimen-No $(\%)$} \\
\hline Preferred $1^{\text {st }}$-line & $135(73)$ & $462(82.9)$ & $598(80.5)$ & \\
\hline Alternative $1^{\text {st }}$-line & $46(24.9)$ & $93(16.7)$ & $139(18.7)$ & \\
\hline Second line & $4(2.2)$ & $2(0.40)$ & $6(0.80)$ & \\
\hline
\end{tabular}

Asterisk(*), shows significant difference; OIs, opportunistic illnesses 
Table 2: Outcomes of treatment of the study cohorts stratified by treatment status at TASH and ZMH ART clinics at the end of follow-up period, Ethiopia, 2013.

\begin{tabular}{|c|c|c|c|c|}
\hline Variables & ART and IPT ( $N=185)$ & ART Only (N=557) & Overall $(\mathrm{N}=742)$ & P-Value \\
\hline Tuberculosis disease - No $(\%)$ & $5(2.7)$ & $75(13.50)$ & $80(10.78)$ & $<0.001^{*}$ \\
\hline Month to TB event & 15.6 & 8.97 & $9.22(8.12-10.32)$ & $<0.001 *$ \\
\hline HIV progression-No (\%) & $8(4.33)$ & $50(9.0)$ & $58(7.8)$ & 0.055 \\
\hline Rapid progression & $1(0.54)$ & $27(4.84)$ & $28(3.77)$ & $0.029 *$ \\
\hline Slow progression & $7(3.78)$ & $23(4.13)$ & $30(4.04)$ & \\
\hline Adverse events - No $(\%)$ & $12(6.5)$ & $10(1.8)$ & $22(3.0)$ & $0.002^{*}$ \\
\hline \multicolumn{5}{|l|}{ Follow-up CD4 } \\
\hline Median & 379.50 & 249.50 & 283.50 & \\
\hline Interquartile range & $289-517$ & $158-335.5$ & $186-379$ & \\
\hline \multicolumn{5}{|l|}{ Hemoglobin (mg/dL) } \\
\hline Median & 15.00 & 14.00 & 14.00 & \\
\hline Interquartile range & $13.5-16$ & $13-15$ & $13-15.5$ & \\
\hline Median ALT (Units/mL) & 30.50 & 27.50 & 28.00 & \\
\hline Median AST & 33.75 & 33.50 & 33.50 & \\
\hline Median BUN value & 19.75 & 20.00 & 20.00 & \\
\hline Median Cr level & 0.76 & 0.74 & 0.74 & \\
\hline
\end{tabular}

Asterisk (*), shows significant difference; ALT, alanine transaminase; AST, aspartate transaminase; BUN, blood urea nitrogen; $\mathrm{Cr}$, creatinine

As shown in Table 2, the incidence of TB in patients receiving IPT plus ART was $5(2.7 \%)$ compared to 75 $(13.5 \%)$ in those receiving ART only $(\mathrm{p}<0.001)$. There were $8(4.3 \%)$ cases of HIV progression to AIDS among the patients who took IPT plus ART compared to the 50 $(9.0 \%)$ cases in those receiving ART only $(p=0.055)$. Higher proportion of rapid HIV progressions was shown in patients receiving ART alone compared to those receiving IPT plus ART ( $\mathrm{p}=0.029)$. However, there were $12(6.5 \%)$ cases of adverse events encountered among the patients receiving IPT plus ART compared to the 10
$(1.8 \%)$ cases among those receiving ART only $(\mathrm{p}=0.002)$ (Table 2).

\section{Risks of incidence of tuberculosis}

Tuberculosis incidence rates were calculated using person-years (PYs) of follow-up as the denominator for the entire cohort and between the two primary exposure groups (Table 3). Patients who received ART alone had a tuberculosis incidence rate of 7.44/100PYs (95\% CI 7.19-7.69); and those who received IPT plus ART had a rate of $1.80 / 100 \mathrm{PYs} \quad(95 \%$ CI $0.92-2.68)$.

Table 3: Incidence rate of tuberculosis for treatment categories of the cohort at TASH and ZMH ART clinics, Ethiopia, 2013.

\begin{tabular}{|lllll|}
\hline Exposure category & Person-years & TB cases & IR (per 100 PYs) & IRR \\
\hline ART alone & 1008 & 75 & $7.44(7.19-7.69)$ & 1 \\
\hline IPT plus ART & 280 & 5 & $1.80(0.92-2.68)$ & $0.24(0.12-0.35)$ \\
\hline Overall & 1288 & 80 & $6.37(5.24-7.50)$ & \\
\hline
\end{tabular}

IR, Crude incidence rate; TB, tuberculosis; IRR, incidence rate ratio

Both univariable (unadjusted) and multivariable (adjusted) regression analyses (Table 4) revealed the treatment by IPT plus ART was significantly associated with a decreased risk of tuberculosis (adjusted odds ratio [AOR] 0.24; 95\% CI 0.09-0.63; p = 0.004) compared to the treatment by ART only. These analyses also showed previous tuberculosis history was significantly associated with the increased risks of tuberculosis (AOR 3.10; 95\% CI 1.53-6.27; p $=0.002$ ) compared to patients free of previous tuberculosis disease. In addition, using a baseline CD4 lymphocyte count of $\geq 350$ cells $/ \mathrm{mL}$ as the reference group in the univariable and multivariable 
analyses, CD4 lymphocyte counts $<350$ cells/mL were significantly associated with the increased risks of tuberculosis (Crude Odds Ratio [COR] 4.02; 95\% CI 1.44-8.20; $\mathrm{p}=0.008$ and AOR 2.99; 95\% CI 1.10-7.09; $\mathrm{p}=0.04)$.

\section{Risks of HIV progression to AIDS}

The univariable regression analysis (Table 4) of the treatment by IPT plus ART was marginally associated with a reduced risk of HIV progression to AIDS (COR $0.48 ; 95 \%$ CI $0.22-1.02 ; \mathrm{p}=0.058$ ) compared to the treatment by ART only. However, the multivariable analysis showed non-significant association (AOR 0.61; 95\% CI 0.26-1.44; $\mathrm{p}=0.26$ ). Both univariable and multivariable regression analyses also revealed that patients with age between 30 to 39 years (AOR 3.39; 95\% CI $1.27-9.03 ; \mathrm{P}=0.015$ ) and 40 to 49 years (AOR $3.19 ; 95 \%$ CI 1.10-9.26; $\mathrm{P}=0.032$ ) had increased risks of HIV progression to AIDS compared to the reference group with age between 18 to 29 years. Moreover, in univariable analysis considering patients with baseline CD4 cell counts $\geq 350$ cells $/ \mathrm{mL}$ as a reference group, patients with baseline CD4 cell counts $<350$ cells/mL were marginally associated with the increased risks of HIV progression to AIDS (COR 2.67; 95\% CI 0.95-7.53; $\mathrm{p}=0.06$ ); multivariable analysis, however, revealed nonsignificant association (AOR 2.49; 95\% CI 0.71-8.75; $\mathrm{p}=0.15$ ). Drug addiction was not significantly associated with the risks of HIV progression to AIDS both in univariable and multivariable regression analyses (AOR $1.03 ; 95 \%$ CI $0.51-2.09 ; \mathrm{p}=0.92$ ).

Table 4: Regression analyses for association of risks of incidence of TB, HIV progression and adverse events among the study cohorts at TASH and ZMH ART clinics, Ethiopia, 2013.

\begin{tabular}{|c|c|c|c|c|}
\hline \multirow[t]{2}{*}{ Outcomes and risks } & \multicolumn{2}{|l|}{ Univariable } & \multicolumn{2}{|l|}{ Multivariable } \\
\hline & $\operatorname{COR}(95 \% \mathrm{CI})$ & $\mathrm{P}$ & AOR $(95 \% \mathrm{CI})$ & $\mathrm{P}$ \\
\hline \multicolumn{5}{|c|}{ Tuberculosis Incidence } \\
\hline \multicolumn{5}{|l|}{ Treatment status } \\
\hline ART only & 1 & & 1 & \\
\hline IPT and ART & $0.18(0.07-0.45)$ & $<0.001$ & $0.24(0.09-0.63)$ & $0.004^{*}$ \\
\hline \multicolumn{5}{|l|}{ Previous TB history } \\
\hline No & 1 & & 1 & \\
\hline Yes & $2.85(1.45-5.61)$ & 0.002 & $3.10(1.53-6.27)$ & $0.002 *$ \\
\hline \multicolumn{5}{|l|}{ Age (Years) } \\
\hline $18-29$ & 1 & & 1 & \\
\hline $30-39$ & $1.44(0.72-2.86)$ & 0.30 & $1.68(0.83-3.39)$ & 0.14 \\
\hline $40-49$ & $1.76(0.84-3.68)$ & 0.13 & $2.37(1.11-5.09)$ & $0.02 *$ \\
\hline$\geq 50$ & $1.89(0.81-4.42)$ & 0.13 & $2.22(0.93-5.30)$ & 0.07 \\
\hline \multicolumn{5}{|c|}{ CD4 cell count (cells/mL) } \\
\hline$\geq 350$ & 1 & & 1 & \\
\hline$<350$ & $4.02(1.44-8.20)$ & 0.008 & $2.99(1.10-7.09)$ & $0.04 *$ \\
\hline \multicolumn{5}{|c|}{ HIV progression to AIDS } \\
\hline \multicolumn{5}{|l|}{ Treatment status } \\
\hline ART only & 1 & & 1 & \\
\hline IPT and ART & $0.48(0.22-1.02)$ & 0.058 & $0.61(0.26-1.44)$ & 0.26 \\
\hline \multicolumn{5}{|l|}{ Age (Years) } \\
\hline $18-29$ & 1 & & 1 & \\
\hline $30-39$ & $3.13(1.19-8.25)$ & 0.021 & $3.39(1.27-9.03)$ & $0.015^{*}$ \\
\hline $40-49$ & $2.89(1.02-8.14)$ & 0.045 & $3.19(1.10-9.26)$ & $0.032 *$ \\
\hline$\geq 50$ & $2.61(0.80-8.49)$ & 0.110 & 2. $18(0.84-9.39)$ & 0.093 \\
\hline \multicolumn{5}{|c|}{ CD4 cell count (cells/mL) } \\
\hline$\geq 350$ & 1 & & 1 & \\
\hline$<350$ & $2.67(0.95-7.53)$ & 0.06 & $2.49(0.71-8.75)$ & 0.15 \\
\hline \multicolumn{5}{|l|}{ Drug Addiction } \\
\hline No & 1 & & 1 & \\
\hline Yes & $1.07(0.54-2.09)$ & 0.84 & $1.03(0.51-2.09)$ & 0.92 \\
\hline \multicolumn{5}{|l|}{ Adverse Event } \\
\hline \multicolumn{5}{|l|}{ Treatment status } \\
\hline ART only & 1 & & 1 & \\
\hline
\end{tabular}




\begin{tabular}{|cllll|}
\hline IPT and ART & $3.76(1.60-8.86)$ & 0.002 & $3.33(1.35-8.19)$ & $0.009^{*}$ \\
\hline Age $($ Years $)$ & & & & \\
\hline $18-29$ & 1 & & 1 & 0.44 \\
\hline $30-39$ & $0.60(0.18-1.99)$ & 0.40 & $0.62(0.18-2.12)$ & 0.59 \\
\hline $40-49$ & $1.28(0.40-4.13)$ & 0.67 & $1.41(0.39-5.04)$ & 0.28 \\
\hline$\geq 50$ & $1.44(0.37-5.51)$ & 0.59 & $2.24(0.50-9.95)$ & \\
\hline ART regimen & & & 1 & $0.001^{*}$ \\
\hline Preferred 1 ${ }^{\text {st }}$-line & 1 & & $4.35(1.77-10.47)$ & 0.999 \\
\hline Alternative 1 $1^{\text {st }}$-line & $4.58(1.94-10.67)$ & 0.001 & 0.001 & \\
\hline Second line & 0.001 & 0.999 & & \\
\hline
\end{tabular}

Asterisk (*), shows significant difference

\section{Risks of adverse events}

As shown in Table 4, univariable and multivariable regression analyses of the treatment by IPT plus ART revealed a significant association with the increased risks of adverse events (AOR 3.33; 95\% CI 1.35-8.19; $\mathrm{p}=0.009$ ) compared to the treatment by ART only. In addition, considering patients on preferred first-line ART regimens as a reference category, both adjusted and unadjusted regression analyses showed statistically significant association of use of alternative first-line ART regimens with the increased risks of adverse events (AOR $4.35 ; 95 \%$ CI $1.77-10.47 ; \mathrm{p}=0.001$ ).

\section{DISCUSSION}

Our comparative study found a substantial effect of the combined use of IPT with ART on the reduction of incidence rate of tuberculosis from 7.44/100PYs to 1.80 cases per 100PYs in this population. This treatment by IPT plus ART reduced the incidence of tuberculosis by $76 \%$ compared to the treatment of ART only. This benefit of IPT was found to be comparable to various previous studies. ${ }^{1,2,10,13}$ In addition, the use of IPT (for 6 months) plus ART showed a tuberculosis disease protection of about 16 months compared to the ART alone $(\mathrm{p}<0.001)$. This is similar to a previous study which demonstrated the duration of protective effect of TB preventive therapy for HIV-infected patients ranging from 12 months to 3 years. ${ }^{14} \mathrm{~A}$ literature report has also shown that TB risk protection in HIV patients on ART could persist for about 2 years after the initiation of IPT. ${ }^{3}$ Moreover, in settings with a high TB prevalence, optimal protective effect of IPT was maintained for 18 months in patients on ART. ${ }^{17}$

Compared to HIV patients with age between 18-29 years, HIV patients with age between $40-49$ years had a 2.37 times higher risks of getting TB $(\mathrm{p}=0.02)$. This was a partial agreement with a South African study which demonstrated greater risks of tuberculosis in ages between 30-39 years $($ IRR $=1.34 ;$ IQR $0.98-1.85)$ and $40-49$ years $(\mathrm{IRR}=1.77 ; 95 \% \mathrm{CI} 1.26-2.51) .{ }^{13} \mathrm{~A}$ randomized trial and a cohort of South African gold miners had also shown increasing risks of tuberculosis along the age strata. ${ }^{18,20}$ Our cohort revealed that increasing age was mainly associated with a trend of increasing risks of tuberculosis. This observation was logical, as older age is usually associated with a higher risk of tuberculosis infection and disease.

The level of immunodeficiency was significantly associated with tuberculosis incidence in this cohort. Compared to HIV patients with CD4 cell counts $\geq 350$ cells/mL, HIV patients with CD4 cell counts $<350$ cells $/ \mathrm{mL}$ had a 2.99 times higher risks of tuberculosis infection ( $\mathrm{p}=0.04$ ). This is consistent to several previous studies in South Africa and Gambia demonstrating lower baseline CD4 cell counts accrued much greater persontime compared to higher CD4 cell strata. ${ }^{15,21,22,23,24}$

Moreover, this study found a previous diagnosis of tuberculosis noted at baseline was associated with the increased risks of tuberculosis during the follow-up. Compared to HIV patients with no previous history of tuberculosis at baseline, HIV patients with documented previous tuberculosis infection at baseline had a 3.1 times higher risks of getting tuberculosis infection. This is comparable to three previous studies which found the recurrence of tuberculosis to be associated with lower CD4 cell counts. ${ }^{7,21,25}$ This is because the prevalence of culture proven active infection and tuberculosis disease increases steeply with dropping CD4 cell counts.

Both univariable and multivariable analyses of our data showed no statistically significant difference of the treatment by IPT plus ART on the overall risks of HIV progression to AIDS compared to the ART only treatment. This is similar to a literature which showed no overall effect of IPT on progression to AIDS ${ }^{26}$ However, the treatment by IPT plus ART significantly delayed the time of HIV progression to AIDS ( $\mathrm{p}=0.029)$ compared to the ART only. This is consistent to a study and a literature from Harvard business school. ${ }^{4,18}$ However, this study did not find previous data that purely compared the impacts of the two treatment categories on risks of HIV progression to AIDS. 
Patients with age between 30 to 39 years $(p=0.015)$ and 40 to 49 years $(p=0.032)$, respectively, had a 3.39- and 3.19-times higher risks of HIV progression to AIDS than patients of age 18-29 years. Consistent to this study, a France study has shown an increased risk of HIV progression to AIDS in older HIV patients on ART compared to younger patients because of slower reconstitution of CD4 cells in older patients. ${ }^{27}$ This is an opposite finding to a New York study that demonstrated age as a non-predictor of HIV progression to AIDS. ${ }^{28}$ However, about two-thirds of patients in this cohort were in the age between 30 to 49 years, accommodating more number of patients with disease progressed to AIDS, compared to older and younger patients. This could explain the inconsistence.

Without adjustment for multivariable, HIV patients with CD4 cell counts $<350$ cells/mL had a 2.67 times higher risks of HIV progression to AIDS than HIV patients with CD4 cell counts $\geq 350$ cells $/ \mathrm{mL}$. However, the multivariable analysis revealed non-significant association of the lower baseline CD4 cell counts $(<350$ cells $/ \mathrm{mL}$ ) with the risks of HIV progression to clinical AIDS when compared to the higher baseline CD4 cell counts $(\geq 350$ cells $/ \mathrm{mL})$. This finding was contradictory to a metaanalysis report which explained HIV-infected CD4 lymphocytes may lead to progression from HIV infection to clinical AIDS. ${ }^{4}$ Moreover, a veteran's cohort in New York showed progression to AIDS correlated strongly with baseline CD4 lymphocyte counts. ${ }^{29}$ These two studies, however, did not stratify baseline CD4 cell counts and had no comparisons between lower and higher CD4 counts as this study did. This methodological difference could explain the variability.

Drug addiction was not significantly associated with the risks of HIV progression in this study both in adjusted and unadjusted regression analyses. A New York cohort similar to this study revealed non-significant association of drug addiction with risks of HIV progression to AIDS both in male and female drug users except for crack cocaine users. ${ }^{30}$ In addition, findings of a cohort study in Boston demonstrated a clinically and statistically nonsignificant effect of heavy alcohol consumption on HIV progression among persons on ART, controlled for medication adherence. ${ }^{31}$ Contradictory to these studies, tobacco smoking was shown in a US study to increase risks of AIDS-defining illnesses like respiratory infections and to decrease immune and virologic responses to HAART. ${ }^{32}$ Consistently, a systemic review had identified 10 studies using progression to AIDS as an end point; of which nine found no relation with tobacco smoking. ${ }^{33}$ However, the findings of our study did not have crack cocaine users and the number of smokers was very low. This may explain the difference.

The multivariable regression analysis of the treatment by IPT plus ART in HIV-infected patients was associated with a 3.33 times higher risks of experiencing adverse events than the HIV-infected patients receiving ART alone. This is similar with studies that demonstrated adverse effects leading to discontinuation of treatment being more common in trials using multi-drug combination therapy as opposed to a drug combination therapy. ${ }^{4,6}$ A metaanalysis in Switzerland and a cohort in Botswana also found a trend suggesting that patients receiving IPT experienced more adverse events, particularly related to hepatotoxicity. ${ }^{19,34}$ Moreover, in a systemic review of tuberculosis prevention in HIV infection, higher risks of drug reaction were found to be associated with greater number of drugs used. ${ }^{35}$

Receiving alternative first-line ART regimens by HIVinfected patients was associated with approximately fourfold increased risks of adverse events in comparison to patients who received the preferred first-line ART regimens. Consistent to this study, among patients receiving both ART and IPT, the risk of adverse event, especially peripheral neuropathy was found to be potentiated if stavudine (drug in alternative $1^{\text {st }}$ line) or didanosine is used. ${ }^{16}$ Moreover, our study did not find previous studies associating risks of adverse events with potential covariates.

Though baseline demographic characteristics were nearly balanced and long duration of follow-up was ensured for reliable outcome ascertainment, there were some limitations to this analysis, which was observational and retrospective. First, data of this study were abstracted from medical records, not were prospectively collected; and may suffer from missing informations that could result in under- or over-estimation of the outcomes. The data abstraction and collection process was, however, closely monitored by trained supervisors; and extensive quality assurance measures were employed. A second limitation is that the study considered patients attending HIV outpatient clinics, and did not include individuals with undiagnosed HIV infection who may have an increased risk of tuberculosis; thus, the study could have underestimated the overall risk of tuberculosis in the population. However, adjustment for CD4 cell count at enrollment should help in interpretation. Finally, it should be noted that this study was a prevalent follow-up, probably with some underrepresentation of patients whose HIV disease progressed rapidly, and thus died before eligible to treatment and chronic HIV care follow-up.

\section{CONCLUSION}

The present comparative study demonstrated the useful effects of IPT plus ART on the reduction of tuberculosis incidence and prolongation of time to tuberculosis event compared to treatment by ART only. In addition, this study found an association of older ages, lower CD4 cell counts, and history of previous tuberculosis with increased risks of tuberculosis infection. The treatment by IPT plus ART also delayed HIV progression to AIDS more significantly than the ART only. Still older ages and lower CD4 cell counts were associated with the higher risks of HIV progression to clinical AIDS. The findings, 
however, showed increased risks of adverse events in the IPT plus ART users compared to the ART only users. Therefore, early initiation of the preferred $1^{\text {st }}$-line ART regimen and IPT; and serious consideration and care for adverse events could optimize the usefulness of IPT plus ART on risks of tuberculosis and HIV progression, especially in HIV-patients with lower CD4 cell counts and older ages.

\section{ACKNOWLEDGEMENTS}

The authors would like to acknowledge the office of Vice President for Research and Technology Transfer of Addis Ababa University for financial support and Haramaya University for granting study leave to first author.

Funding: No funding sources Conflict of interest: None declared

Ethical approval: Approval was obtained from all participating institutions

\section{REFERENCES}

1. Golub JE, Saraceni V, Cavalcante SC, Antonio G, Pacheco AG, Moultona LH, et al. The impact of antiretroviral therapy and Isoniazid preventive therapy on tuberculosis incidence in HIV-infected patients in Rio de Janeiro, Brazil. AIDS. 2007;21 (11):1441-8.

2. Frigati LJ, Kranzer K, Cotton MF, Schaaf HS, Lombard CJ, Zar HJ. The impact of isoniazid preventive therapy and antiretroviral therapy on tuberculosis in children infected with HIV in a high tuberculosis incidence setting. Thorax. 2011;66:496501.

3. Martinson N, Hoffmann C, and Chaisson R. Epidemiology of Tuberculosis and HIV: Recent Advances in Understanding and Responses. Proc Am Thorac Soc. 2010;8: 288-93.

4. Akolo C, Adetifa I, Shepperd S, Volmink J. Treatment of latent tuberculosis infection in HIV infected persons. The Cochrane Collaboration. 2010;1:1-81.

5. Vieira de Souza CT, Hökerberg YHM, Pacheco SJB, Rolla VC, Passos SRL. Effectiveness and safety of isoniazid chemoprophylaxis for HIV-1 infected patients from Rio de Janeiro. Mem Inst Oswaldo Cruz. 2009; 104 (3):462-7.

6. Lawn SD, Wood $\mathrm{R}$ and Wilkinson RJ. Changing Concepts of "Latent Tuberculosis Infection" in Patients Living with HIV Infection. Clinical and Developmental Immunology. 2010;2011:1-9.

7. Pawlowski A, Jansson M, Skold M, Rottenberg ME, Ka llenius G. Tuberculosis and HIV Co-Infection. PLoS Pathogens. 2012;8(2):1-7.

8. Chamie G, Luetkemeyer A, Charlebois E, and Havlir DV. Tuberculosis as Part of the Natural History of HIV Infection in Developing Countries. Clin Infect Dis. 2010;50(3): S245-54.
9. Lawn SD, Ayles H, Egwaga S, Williams B, Mukadi YD, Filho EDS, et al. Potential utility of empirical tuberculosis treatment for HIV-infected patients with advanced immunodeficiency in high TB-HIV burden settings. Int J Tuberc Lung Dis. 2011;15(3):287-95.

10. Frothingham R, Stout JE, Hamilton CD. Current issues in global tuberculosis control. International Society for Infectious Diseases. 2005;9:297-311.

11. Meya DB and McAdam KPWJ. The TB pandemic: an old problem seeking new solutions. J Intern Med. 2007;261:309-29.

12. Sabina Mugusi. Optimization of HIV and tuberculosis co-treatment in Tanzania: drug-drug interactions and clinical outcomes. 2013;1-17.

13. Loeffler AM. Pediatric Tuberculosis. Seminars in Respiratory Infection. 2003;18(4):272-91.

14. Swaminathan S, Menon PA, Gopalan N, Perumal V, Santhanakrishnan RK, Ramachandran R, et al. Efficacy of a Six-Month versus a 36-Month Regimen for Prevention of Tuberculosis in HIV-Infected Persons in India: A Randomized Clinical Trial. PLoS ONE. 2012;7(12):1-9.

15. Golub JE, Astemborski J, Ahmed M, Cronin W, Mehta SH, Kirk GD, et al. Long-term effectiveness of diagnosing and treating latent tuberculosis infection in a cohort of HIV-infected and at risk injection drug users. J Acquir Immune Defic Syndr. 2008;49(5):532-7.

16. Montaner JSG, Hogg R, Wood E, Kerr T, Tyndall $\mathrm{M}$, Levy AR, et al. The case for expanding access to highly active antiretroviral therapy to curb the growth of the HIV epidemic. Lancet. 2006;368:5316.

17. Rhatigan J, Jain S, Mukherjee JS, and Porter ME. Applying the Care Delivery Value Chain: HIV/AIDS Care in Resource Poor Settings. Global Health Delivery Project. 2009;1-13.

18. Mosimaneotsile B, Mathoma A, Chengeta B, Nyirenda S, Agizew TB, Tedla Z, et al. Isoniazid Tuberculosis Preventive Therapy in HIV-Infected Adults Accessing Antiretroviral Therapy: A Botswana Experience, 2004-2006. J Acquir Immune Defic Syndr. 2010;54:71-7.

19. Grant AD, Charalambous S, Fielding KL, Day JH, Corbett EL, Chaisson RE, et al. Effect of Routine Isoniazid Preventive Therapy on Tuberculosis Incidence among HIV-Infected Men in South Africa: A Novel Randomized Incremental Recruitment Study. JAMA. 2005;293(22):2719-25.

20. Sonnenberg P, Glynn JR, Fielding K, Murray J, Godfrey-Faussett P, and Shearer S. How Soon after Infection with HIV Does the Risk of Tuberculosis Start to Increase? A Retrospective Cohort Study in South African Gold Miners. JID. 2005;191:150-8.

21. Lawn SD, Myer L, Edwards D, Bekkera LG and Wood R. Short-term and long-term risk of tuberculosis associated with CD4 cell recovery during antiretroviral therapy in South Africa. AIDS. 2009;23:1717-25. 
22. Lawn SD, Myer L, Edwards D, Bekkera LG and Wood R. Burden of tuberculosis in an antiretroviral treatment programme in sub-Saharan Africa: impact on treatment outcomes and implications for tuberculosis control. AIDS. 2006;20:1605-12.

23. Lawn SD, Myer L, Edwards D, Bekkera LG and Wood R. Short-term and long-term risk of tuberculosis associated with CD4 cell recovery during antiretroviral therapy in South Africa. AIDS. 2009;23:1717-25.

24. Komati S, Shaw PA, Stubbs N, Mathibedi MJ, Malan L, Sangweni P, et al. Tuberculosis risk factors and mortality for HIV-infected persons receiving antiretroviral therapy in South Africa. AIDS. 2010;24:1849-55.

25. Maher D, Harries A, and Getahun H. Tuberculosis and HIV interaction in sub-Saharan Africa: impact on patients and programmes; implications for policies. Tropical Medicine and International Health. 2005;10(8):734-42.

26. Fawzi WW, Msamanga G, Spiegelman D, Wei R, Kapiga S, Villamor E, et al. Randomized Trial of Multivitamin Supplements and HIV Disease Progression and Mortality. N Engl J Med. 2004;351(1):23-32.

27. Selwyn PA, Algabes P, Hartel D, Buono D, Schoenbaun EE, Klein RS, et al. Clinical Manifestations and Predictors of disease progression in drug users with HIV infection. N Engl J Med. 1992;327(24):1698-1703.

28. Farzadegan H, Hoover DH, Astemborski J, Lyles CM, Margolick JB, Markham RB, et al. Sex differences in HIV-1 viral load and progression to AIDS. The Lancet. 1998;352:1510-14.

29. Webber MP, Schoenbaum EE, Gourevitch MN, Buono D and Klein RS. A prospective study of HIV disease progression in female and male drug users. AIDS. 1999;13:257-62.

30. Samet JH, Cheng DM, Libman H, Nunes DP, Alperen JK, and Saitz R. Alcohol Consumption and HIV Disease Progression. J Acquir Immune Defic Syndr. 2007;46(2):194-9.

31. Gore-Felton C, and Koopman C. Behavioral Mediation of the Relationship between Psychosocial Factors and HIV Disease Progression. Psychosomatic Medicine. 2008;70:569-74.

32. Furber AS, Maheswaran R, Newell JN, and Carroll C. Is smoking tobacco an independent risk factor for HIV infection and progression to AIDS? A systemic review. Sex Transm Infect 2007;83:41-6.

33. Gutierrez EB, Gomes V, Picone CM, Suga H and Atomiya AN. Active tuberculosis and Mycobacterium tuberculosis latent infection in patients with HIV/AIDS. HIV Medicine. 2009;10:564-72.

34. Bucher HC, Griffith LE, Guyatt GH, Sudre P, Naef M, Pedram Sendi P, et al. Isoniazid prophylaxis for tuberculosis in HIV infection: a meta-analysis of randomized controlled trials. AIDS. 1999;13:501-7.

35. Wilkinson D. Drugs for preventing tuberculosis in HIV infected persons. The Cochrane Library $2003 ;(4): 1-6$.

doi:10.5455/2319-2003.ijbcp20140203

Cite this article as: Edessa D, Woldeyes T, Shibeshi W. Comparison of effects of isoniazid plus ART and ART only regimen on the incidence of tuberculosis and HIV progression in HIV positive patients: a retrospective cohort study at two hospitals in Addis Ababa, Ethiopia. Int J Basic Clin Pharmacol 2014;3:54-62. 